\title{
MEMANTINE - NEUROPROTECTIVE DRUG IN AGING BRAIN
}

\author{
Dominika Karolczak ${ }^{1}$, Emilia Sawicka ${ }^{2}$, Jolanta Dorszewska ${ }^{2}$, Anna Radel ${ }^{1}$, \\ Magdalena Bodnar ${ }^{3}$, Agata BŁaszczyK ${ }^{1}$, Joanna Jagielska ${ }^{4}$, Andrzej MarszaŁeK ${ }^{3,5,6}$
}

\author{
1Electron Microscopy Laboratory, Department of Clinical Pathomorphology, Poznan University of Medical Sciences, \\ Poznan, Poland \\ ${ }^{2}$ Neurobiology Laboratory, Department of Neurology, Poznan University of Medical Sciences, Poznan, Poland \\ 3 Department of Clinical Pathomorphology, Collegium Medicum in Bydgoszcz, Nicolaus Copernicus University in Torun, \\ Poland \\ ${ }^{4}$ Department of Bioinformatics and Computational Biology, Poznan University of Medical Sciences, Poznan, Poland \\ ${ }^{5}$ Department of Oncologic Pathology, Poznan University of Medical Sciences, Poznan, Poland \\ 6Department of Oncologic Pathology, Greater Poland Cancer Center, Poznan, Poland
}

\begin{abstract}
Aging is the process of progressive accumulation of changes over time, which is additionally connected with increasing susceptibility to some diseases and ultimately leads to death. Aging is associated mainly with loss of permanent cells, e.g. in heart, skeletal muscle and brain. During aging neurons die mainly in the apoptotic way. Apoptosis can be divided into three phases: initiation, execution and degradation. During the execution phase activation of specific enzymes, caspases, is observed. These enzymes are responsible for initiation of the death machinery. Caspase- 9 is connected with the internal pathway of apoptosis, which begins at the mitochondrium in response to apoptotic stimulants, such as free radicals, UV radiation or chemotherapeutics. Before the executive phase starts, cytochrome $c$ leaks from the mitochondrium to the cytoplasm, where it joins to the protein Apaf- 1 and procaspase- 9 and forms a complex called the apoptosome. Then procaspase- 9 is converted by autolysis to caspase-9, which subsequently activates procaspase- 3 to the active form which ultimately leads to apoptosis. Immunohistochemical analysis demonstrated a small decrease in caspase- 9 and caspase- 3 activation during normal aging and an increase in this process after application of stress factors. Also increased apoptosis in the cerebrum after administration of a drug for Alzheimer disease, memantine, to aging rats was observed. Taken together, the results obtained in this study seem to confirm the neuroprotective effect of memantine on increasing levels of cells with active caspase-3 and active caspase-9. It probably improves caspase-dependent apoptosis in the aging brain.
\end{abstract}

Key words: apoptosis, caspase-3, caspase-9, aging, brain, memantine.

\section{Introduction}

Aging is the process of progressive accumulation of changes over time, which is additionally connected with increasing susceptibility to some diseases and ultimately leads to death [1]. Aging is associated mainly with loss of permanent cells, e.g. in the heart, skeletal muscle and brain [2]. The aging brain is characterized by loss of neurons. This process is mostly visible in the nucleus caudatus and in some subcortical nuclei. Losses are accompanied by changes in the dendrites. Fields of dendrites decrease in size due to their loss, fragmentation, and shrinking. This also leads to a reduction in the number of synapses and to the alteration of interneuronal connections. Already published results of experimental work [3] show that in the aging brain changes occur in perikarya in the nucleus. As a result of such changes one can observe change in activity of tran- 
scription and translation. Aging is also characterized by a deficiency of neurotransmitters such as acetylcholine (Ach) and dopamine. Moreover, in the old brain deposition of amyloid $\beta(A \beta)$ and the formation of neurofibrillary tangles is observed. During the aging process neurons die mainly in the apoptotic way. Apoptosis is identified on the basis of characteristic morphological changes in the structure of cells. This process is accompanied by cell shrinkage due to water loss and chromatin condensation with simultaneous displacement of the nuclear membrane. Finally, it leads to the reorganization of cytoskeleton and loss of microtubular structures. The apoptotic cell breaks connections with neighbouring cells and takes on a distinctive rounded shape, accompanied by the formation of specific bulges in the cell membrane. This is the starting point for formation of so-called apoptotic bodies, which are surrounded by plasma membrane, while in the interior phase they contain organelles along with fragments of chromatin. Apoptotic bodies are phagocytosed by neighbouring cells [4]. Apoptosis can be divided into three phases: initiation, execution and degradation. During the execution phase activation of specific enzymes, caspases, is observed. These enzymes are responsible for initiation of the death machinery. Caspase-9 is connected with the internal pathway of apoptosis, which begins at the mitochondrium in response to apoptotic stimulants, such as free radicals, UV radiation or chemotherapeutics. Before the executive phase starts, cytochrome c leaks from the mitochondrium to the cytoplasm, where it joins to the protein Apaf-1 and procaspase- 9 and forms a complex called the apoptosome. Then procaspase- 9 is converted by autolysis to caspase-9, which subsequently activates procaspase- 3 to the active form which ultimately leads to apoptosis [5]. During neurodegenerative diseases, such as Alzheimer disease (AD), apoptosis is enhanced. In such cases excessive neuronal loss is observed and leads to clinical signs of disease. Alzheimer disease is caused by excitotoxic action of glutamate. This particle is excessively released from synapses or its uptake is inhibited. Such accumulation excessively stimulates N-methyl-Daspartate (NMDA) receptors. It was proved that in $\mathrm{AD}$ brains a low concentration of glutamate is sufficient to stimulate NMDA receptors. As a therapeutic model for patients with $\mathrm{AD}$ the blockage of NMDA receptors as a target of neuroprotective cure was speculated [6]. We examined in this study if the Alzheimer's disease drug memantine (3,5-dimethyl-1-adamantamine) affects apoptosis in the brain of old rats and if it has any neuroprotective action.

\section{Material and methods}

Adult female Wistar rats aged 3.0-3.5 months, weighing about $250 \mathrm{~g}$, and 18-24 months, weighing 300-400 g, were used. Conditions of animal husbandry used for this study were standardized as follows: standard feed, free access to water and constant ambient temperature $\left(21^{\circ} \mathrm{C}\right)$. On the last day of the experiment animals were anaesthetized with halothane. Then after decapitation heads were immersed in liquid nitrogen. Then from rat brains the following three structures were taken: grey matter (GM) of the cerebral cortex (parietal lobe), subcortical white matter (WM) (corpus callosum) and cerebellum (for analysis of granule cells and Purkinje cells). For the experiment we obtained approval by the local ethics committee in December 2007 (no. 74/2007).

\section{Allocation of animals to test groups}

To investigate the neuroprotective action of memantine animals were divided into 4 experimental groups: control I -5 young rats (3-3.5 months); control II -5 old rats (18-24 months); control III -5 old rats (18-24 months) which for 14 days were administered water by intragastric catheter; and group IV the study group, consisting of 6 old rats which for 14 days were fed with memantine (Ebixa from Lundbeck company) by intragastric catheter in a dose of $20 \mathrm{mg} / \mathrm{kg} /$ day.

\section{Determination of the level of cells with active caspase- 3 and active caspase-9 by immunohistochemical staining}

Preparation of slides: Rat tissues taken after decapitation were placed in Bayker's fixative (a solution of formalin and calcium chloride), then divided into brain and cerebellum, and dehydrated sequentially in ethanol at increasing concentrations and finally in benzene and embedded in paraffin. Three-micron thick slides were applied to silanized glass and then deparaffinized with xylene and rehydrated in decreasing concentrations of ethanol.

Uncovering the antigen and the blocking of endogenous peroxidase activity: Sections were immersed for $40 \mathrm{~min}$ in citrate buffer ( $\mathrm{pH}$ 6.0) with proteinase $\mathrm{K}$ in a boiling water bath and then rinsed three times in PBS $(0.9 \%$ solution of $\mathrm{NaCl}$ in phosphate buffer). In order to inactivate endogenous peroxidase slides were immersed in a solution of $3 \%$ hydrogen peroxide for $10 \mathrm{~min}$ at room temperature. To block the background a $5 \%$ solution of bovine serum albumin (BSA) in PBS was used.

Incubation with antigens: Sections were incubated for $30 \mathrm{~min}$ with primary antibodies (rabbit polyclonal IgG antibody binding to P17 fragment of active caspase-3, Abcam cat. no. AB2302) and rabbit polyclonal IgG antibody binding to a fragment consisting of 17 amino acid residues of active caspase-9, Sigma-Aldrich Logistik $\mathrm{GmbH}$ cat. no. C7729) diluted $1: 50$ in 1\% $\mathrm{BSA}$ in a moist chamber at $37^{\circ} \mathrm{C}$. Then material was washed in PBS and incubated for $20 \mathrm{~min}$ with the sec- 
ondary antibody (antirabbit IgG antibody conjugate with horseradish peroxidase from Invitrogen company) of this same dilution as primary antibody (in $1 \%$ BSA) and in the same conditions (temperature of $37^{\circ} \mathrm{C}$, moist chamber).

Final laboratory procedure: Colour reaction was carried out for $7 \mathrm{~min}$ using, as a substrate for peroxidase, a solution containing 3\% hydrogen peroxide, $5 \mathrm{mM}$ Tris- $\mathrm{HCl}$ buffer at $\mathrm{pH} 7.6$ in a ratio of $1: 100$, and DAB as chromogen. Mayer's hematoxylin solution ( $3 \mathrm{~min}$ ) was used for counterstaining of cell nuclei. The whole staining procedure was carried out at room temperature.

\section{Statistical calculations}

The number of apoptotic cells was counted by ImageJ program. The univariate variance analysis ANOVA was used to measure dependence between animal groups. The significance level is $\mathrm{p}<0.05$. Then, for the ANOVA test the post hoc Tukey-Kramer test was used. All statistics were carried out using a statistical program for small abundance - StatX (Cytel Studio version 8.0, Cytel Inc., Cambridge, MA, USA).
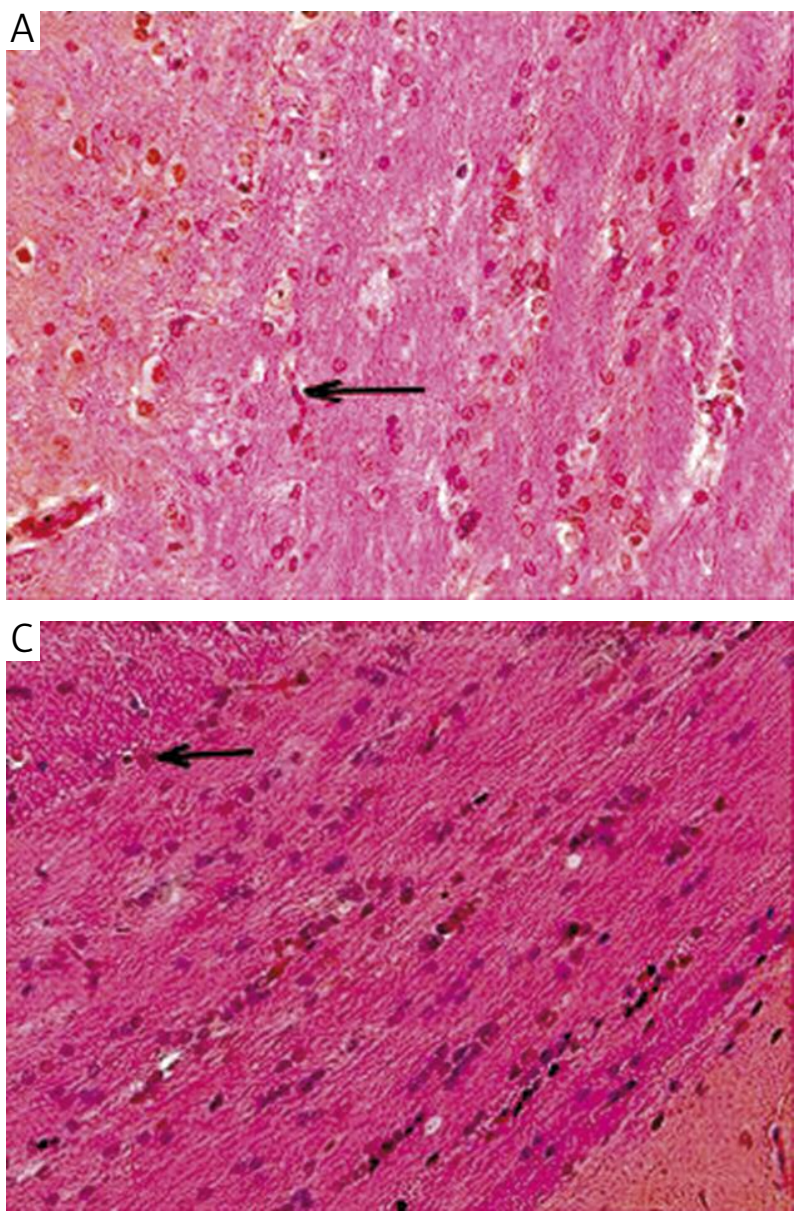

\section{Results}

\section{Caspase -3 activation in rat brains}

To examine the number of cells with active caspase-3 using immunohistochemistry, three areas of the rat brain were analyzed: grey matter of the parietal lobe (cerebral cortex), subcortical white matter (corpus callosum), granule cells and Purkinje cells of the cerebellum. These areas of brains were obtained from four animal groups. Immunoreactivity was observed following incubation with secondary antibody against caspase- 3 in sections from rat brains (Fig. $1 \mathrm{~A}-\mathrm{D})$. In all studied groups the caspase labelling was seen, but in the brains from young rats and old rats fed with memantine the labelling was more extensive. In young rats the number of cells with active caspase- 3 varied in different brain structures (Table I). The smallest differences in number of cells with active caspase- 3 occurred in grey matter: from $20 \%$ to $23 \%$. The largest differences occurred in white matter (from 13\% to $28 \%$ ) and Purkinje cells of the cerebellum (from $11 \%$ to $24 \%$ ) (data not shown). In the control group of aging rats a decline in the level of cells with active
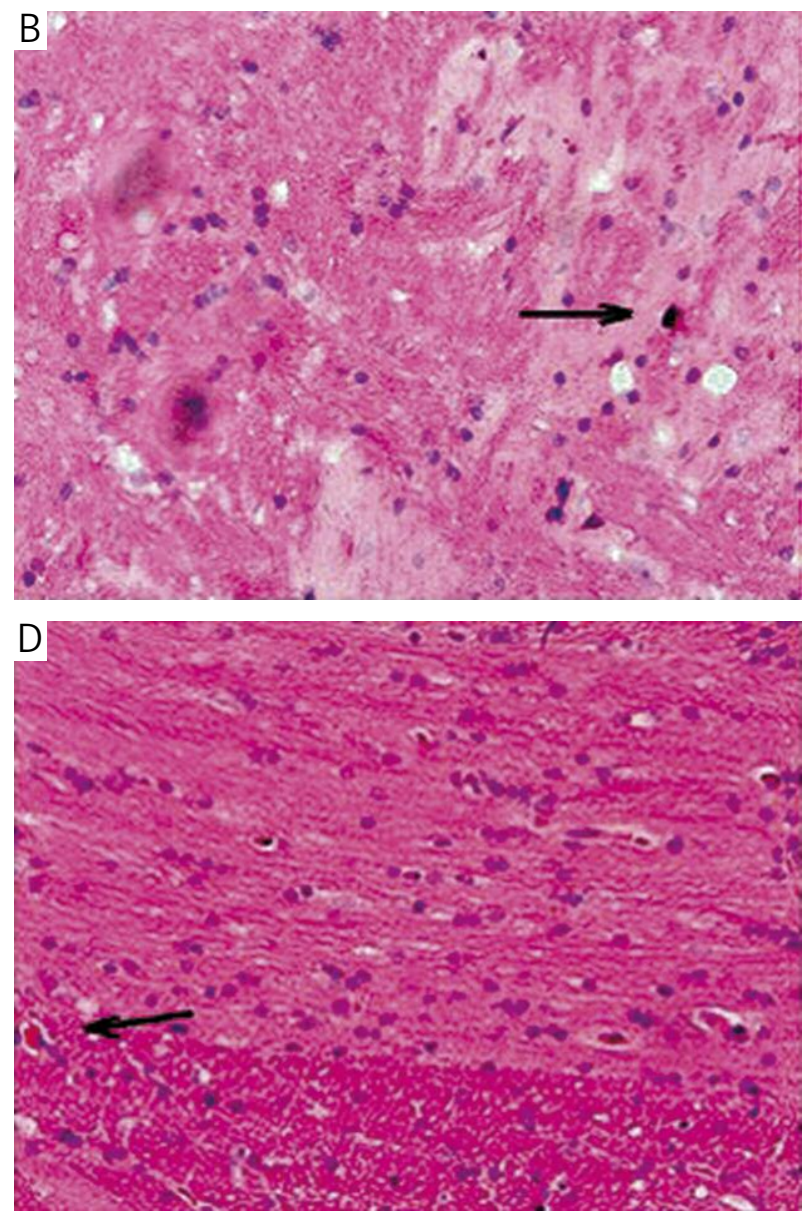

Fig. 1. Immunodetection of activated caspase- 3 in rat brains at magnification $20 \times$. Figure shows white matter of young rat (A), aging rat (B), aging rat after water administration by intragastric catheter $(\mathrm{C})$ and aging rat after memantine administration by intragastric catheter (D). Arrows show apoptotic cells 
Table I. Mean and standard deviation (SD) for analyzed percentage of cells with active caspase-3 in studied brain structures

\begin{tabular}{lcccccccc}
\hline \multirow{2}{*}{ BRAIN STRUCTURE } & \multicolumn{2}{c}{ GROUP I } & \multicolumn{2}{c}{ GROUP II } & \multicolumn{2}{c}{ GROUP III } & \multicolumn{2}{c}{ STUDY GROUP } \\
\cline { 2 - 10 } & MEAN & SD & MEAN & SD & MEAN & SD & MEAN & SD \\
\hline grey matter & 20.80 & 1.30 & 15.20 & 5.80 & 21.80 & 5.50 & 25.20 & 5.40 \\
\hline white matter & 19.60 & 5.90 & 9.80 & 3.40 & 15.40 & 2.10 & 19.70 & 4.00 \\
\hline granule cells & 14.60 & 8.47 & 11.60 & 9.18 & 16.20 & 5.80 & 19.80 & 5.10 \\
\hline Purkinje cells & 15.00 & 9.75 & 8.20 & 5.12 & 9.60 & 2.60 & 10.00 & 1.70 \\
\hline
\end{tabular}

caspase- 3 in all three studied brain structures was observed (Table I). However, the biggest decrease in cells with active caspase- 3 was found in the white matter. In another control group of aging rats, which had an additional stressful factor (administration of water by intragastric catheter), an increase in the level of cells with active caspase- 3 in grey matter in comparison with rats of the same age without a stressful factor and young rats was found (Table I). In the other studied brain areas the level of active caspase- 3 cells was lower than in young rats. Moreover, the biggest difference in the level of cells with active caspase- 3 occurred in the Purkinje cells of the cerebellum between young rats and the aging ones with a stressful factor. In the group of old rats which were fed with memantine by intragastric catheter for 14 days at a neuroprotective dose, we observed an increase of level of cells with active caspase- 3 with grey matter, white matter and cerebellum granule cells in comparison with animals from control groups. In contrast, in cerebellum Purkinje cells we observed an increase in the level of cells with active caspase- 3 but only in comparison with rats at the same age (Table I).

According to the increasing age of experimental animals the level of cells with active caspase- 3 decreased in all analyzed structures of brains, although statistically significant differences were found only in the white matter and Purkinje cells $(\mathrm{p}<0.05$ compared with young rats) (Table II). Furthermore, we demonstrat- ed that an additional stressful factor (in this study water administered by intragastric catheter) led to a statistically significant reduction in the level of cells with active caspase- 3 only in the Purkinje cells ( $\mathrm{p}<0.01$ compared with the same aged animals without a stressful factor). In the other structures analyzed in these animals there was a statistically insignificant increase in the number of cells in which activation of caspase- 3 was stimulated in comparison with animals at the same age without stimulation (Table II). Feeding old rats with memantine at neuroprotective doses caused a statistically significant increase in the number of cells with active caspase- 3 in both grey matter $(\mathrm{p}<0.05$ compared with animals at the same age) and white matter ( $\mathrm{p}<$ 0.01 compared with animals at the same age). However, in the Purkinje cells of these experimental animals the number of cells with active caspase- 3 remained at the level of the aging rats $(\mathrm{p}<0.001$ compared with young animals) (Table II). According to the increasing age of experimental animals there were positive correlations $(\mathrm{R}$ Spearman $+0.9486 ; \mathrm{p}=0.05$ ) between grey matter, white matter and cerebellum. We showed that feeding rats with memantine in neuroprotective doses led to the emergence of a positive correlation between adjacent structures in the central nervous system: grey matter and white matter ( $\mathrm{R}$ Spearman $0.9276 ; \mathrm{p}=0.0077)$ and white matter and granule cells (R Spearman 0.8933; $\mathrm{p}=0.0165)$.

Table II. Moderate level of cells with active caspase- 3 in rat brains after 14 days of memantine feeding and in the control groups

\begin{tabular}{|c|c|c|c|c|c|}
\hline BRAIN STRUCTURES & CONTROL I & CONTROL II & CONTROL III & STUDY GROUP & $\mathbf{P}$ \\
\hline grey matter & $20.8 \pm 1.3$ & $15.2 \pm 5.8$ & $21.8 \pm 5.5$ & $25.2 \pm 5.4 \#$ & 0.0298 \\
\hline white matter & $19.6 \pm 5.9$ & $9.8 \pm 3.4^{+}$ & $15.4 \pm 2.1$ & $19.7 \pm 4.0^{++}$ & 0.0033 \\
\hline granule cells & $18.2 \pm 2.6$ & $14.5 \pm 7.5$ & $16.2 \pm 5.8$ & $19.8 \pm 5.1$ & 0.4783 \\
\hline Purkinje cells & $18.7 \pm 5.7$ & $10.2 \pm 2.6^{*}$ & $9.6 \pm 2.6^{* *}$ & $10.0 \pm 1.7^{* * *}$ & 0.0025 \\
\hline $\begin{array}{l}\text { Statistically significant differe } \\
\text { Grey matter: } \\
\text { - at the level of significance \# } \\
\text { White matter: } \\
\text { - at the level of significance } \\
\text { - at the level of significance } \\
\text { Purkinje cells: } \\
\text { - at the level of significance * } \\
\text { - at the level of significance } \\
- \text { at the level of significance }\end{array}$ & $\begin{array}{l}\text { the level of: } \\
.05 \text { between contro } \\
.05 \text { between contr } \\
0.01 \text { between con } \\
05 \text { between contro } \\
.01 \text { between contr } \\
0.001 \text { between co }\end{array}$ & $\begin{array}{l}\text { nd study group } \\
\text { d control group II } \\
\text { and study group } \\
\text { control group II } \\
\text { ad control group III } \\
\text { and study group }\end{array}$ & & & \\
\hline
\end{tabular}




\section{Caspase- 9 activation in rat brains}

To examine the number of cells with active caspase-9, the same brain structures were used as in the case of caspase-3: grey matter of the parietal lobe (cerebral cortex), subcortical white matter (corpus callosum), granule cells and Purkinje cells of the cerebellum. Immunoreactivity was seen following incubation with secondary antibody against caspase- 9 in sections from rat brains (Fig. 2 A-D). Similarly as in the case of caspase-3 in all examined rats the labelling differences were seen. In the brains from young rats and old rats fed with memantine the labelling was more extensive. In the young rats' brains the percent of cells with active caspase- 9 was quite high, and varied insignificantly in analyzed brain structures (Table III). The smallest differences in levels of cells with active caspase- 9 occurred in granule cells of the cerebellum (from $20 \%$ to $24 \%$ ), while the largest occurred in grey matter (from 20\% to 35\%) (data not shown). In addition, in the grey matter the highest percentage of cells with active caspase-9 was noted. In the second group of control rats there was seen a decline in the number of cells with active caspase-9. The greatest decrease in level of analyzed cells was observed in the grey matter. Only in granule cells of the cerebellum was a rise of the level of cells with
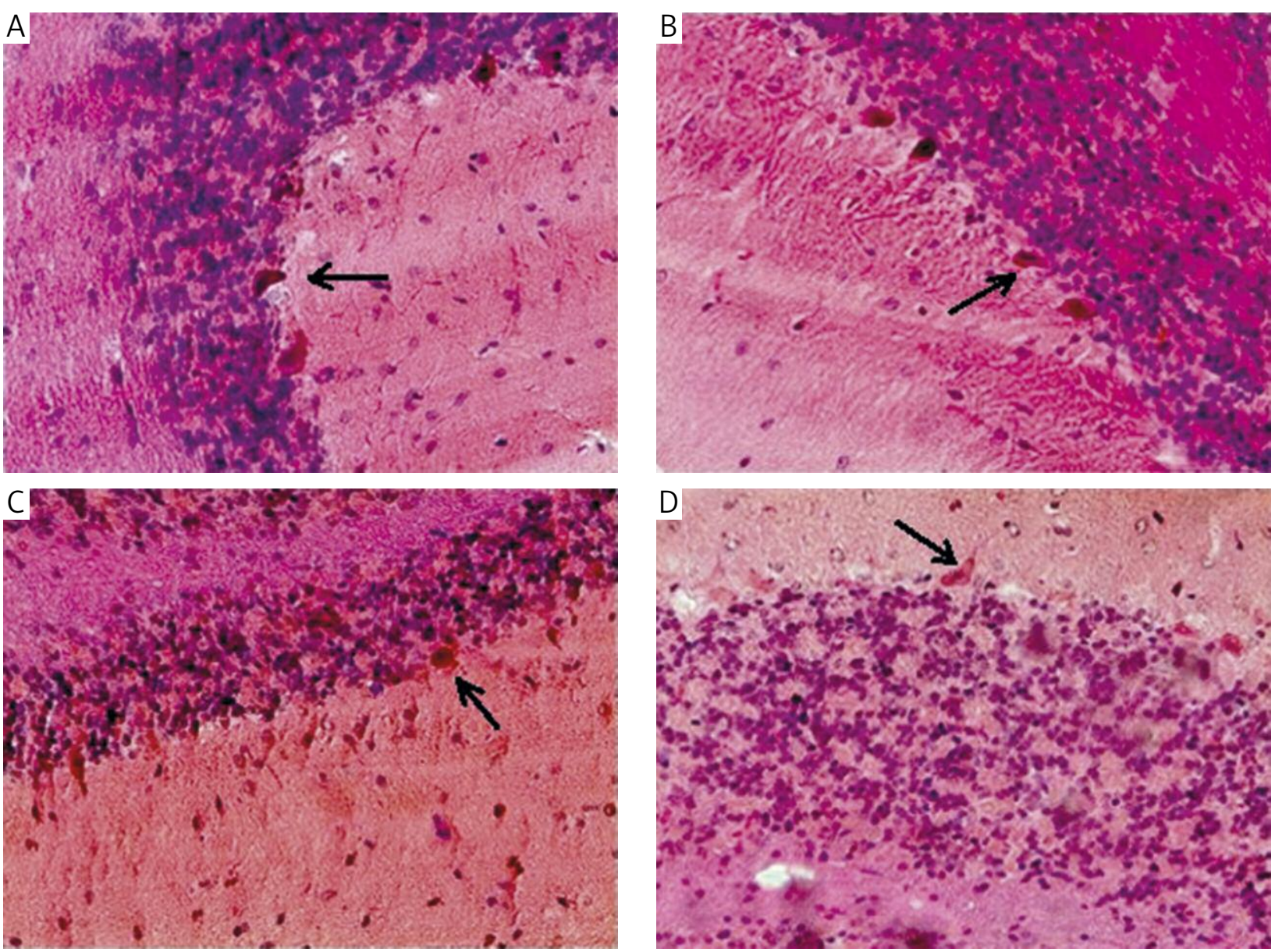

Fig. 2. Caspase-9 immunoreactivity in rat cerebellums at magnification $20 \times$. Figure shows cerebellum of young rat (A), aging rat (B), aging rat after water administration by intragastric catheter $(\mathrm{C})$ and aging rat after memantine administration by intragastric catheter (D). Arrows show big Purkinje cells in apoptosis

Table III. Mean and standard deviation (SD) for analyzed percentage of cells with active caspase-9 in studied brain structures

\begin{tabular}{|c|c|c|c|c|c|c|c|c|}
\hline \multirow[t]{2}{*}{ BRAIN STRUCTURE } & \multicolumn{2}{|c|}{ GROUP I } & \multicolumn{2}{|c|}{ GROUP II } & \multicolumn{2}{|c|}{ GROUP III } & \multicolumn{2}{|c|}{ STUDY GROUP } \\
\hline & MEAN & $\mathrm{SD}$ & MEAN & $\mathrm{SD}$ & MEAN & $\mathrm{SD}$ & MEAN & $\mathrm{SD}$ \\
\hline grey matter & 25.80 & 6.22 & 20.60 & 1.52 & 25.80 & 3.27 & 31.50 & 5.21 \\
\hline white matter & 25.40 & 4.28 & 21.40 & 1.67 & 22.20 & 2.39 & 25.17 & 1.60 \\
\hline granule cells & 21.00 & 1.73 & 25.40 & 3.58 & 22.60 & 4.28 & 25.00 & 5.37 \\
\hline Purkinje cells & 25.20 & 3.77 & 19.20 & 1.79 & 14.40 & 2.88 & 22.17 & 5.74 \\
\hline
\end{tabular}


active caspase-9 found (Table III). In another control group of aging rats, which had an additional stressful factor (administration of water by intragastric catheter), there was found an increase in the level of cells with active caspase-9 in grey matter in comparison with rats either at the same age without a stressful factor or in young rats. In the other studied brain structures, the level of cells with active caspase-9 was lower than in the control group of young rats, except the granule cells of the cerebellum, where that level was increased. In comparison with the second control group of aging rats without any stressful factor, only in the granule cells of the cerebellum was the level of studied cells lower (Table III). In the rest of the analyzed brain structures the labelling was slightly higher at only about from $2 \%$ to $3 \%$. In the group of old rats which were fed with memantine by intragastric catheter for 14 days at a neuroprotective dose, we observed an increase of the level of cells with active caspase-9 with grey matter, white matter and cerebellum granule cells in comparison with animals from previous groups. Only in the cerebellum Purkinje cells was a decrease in the level of cells with active caspase-9 observed. For statistical analysis the results were expressed as mean and standard deviation (Table II). Graphic presentation of these results is illustrated in Fig. 3.

By the statistical analysis we found statistically significant differences of the level of expression of caspase-9 for material from grey matter and Purkinje cells of the cerebellum (Table IV).

\section{Discussion}

During life time a lot of changes in aging brain are accumulated and finally expressed. These changes can be divided into morphological and biochemical. Among the morphological changes in the aging central nervous system we can include decrease in size of dendritic fields, which leads to a decrease in the number of synapses [7]. Another change observed during brain aging is elimination of various types of neurons in strictly defined regions of the brain. For example, in the black matter there is a decrease in the number of dopaminergic neurons [8]. Moreover, during physiological aging there occurs atrophy in the cortex, especially in the frontal cortex, and dying glial cells in the white matter [9]. In living organisms cells may die by necrosis or by apoptosis. In physiological conditions in apoptotic pathways one can ob- serve elimination not only of neurons, but also other nervous cells, such as oligodendrocytes and astrocytes. This phenomenon was confirmed in this study. We demonstrated activation of caspase- 9 and caspase- 3 in brains of young and aging rats.

\section{Caspase- 3 activation in rat brains}

We showed that caspase- 3 activation in young experimental animals does exhibit diversity in the level of expression in the cerebral cortex and in the cerebellum. It was previously demonstrated and described for the cerebral cortex, cerebellum and hippocampus in young monkeys [10]. As it was shown, equal levels of cells with active caspase- 3 and its inactive form, procaspase- 3 , in all analyzed structures of the cerebral cortex and in the cerebellum exist even in one-day-old rats [11]. Additionally it was shown that during ontogenesis the levels of procaspase- 3 and caspase- 3 decrease and become stabilized in 30-day-old rats, and they probably take active part in apoptosis.

In aging rats relevant changes in the number of apoptotic cells could be observed. During the aging process in the cerebral cortex and in the cerebellum again a decrease in gene expression for caspase- 3 is observed [10]. It is probably connected with impairment of apoptosis in the central nervous system. A decreased number of cells with active caspase- 3 was confirmed in this study. We demonstrated a relevant decrease in the percentage of cells with active caspase- 3 in aging rat brains either in white matter or in Purkinje cells of the cere-

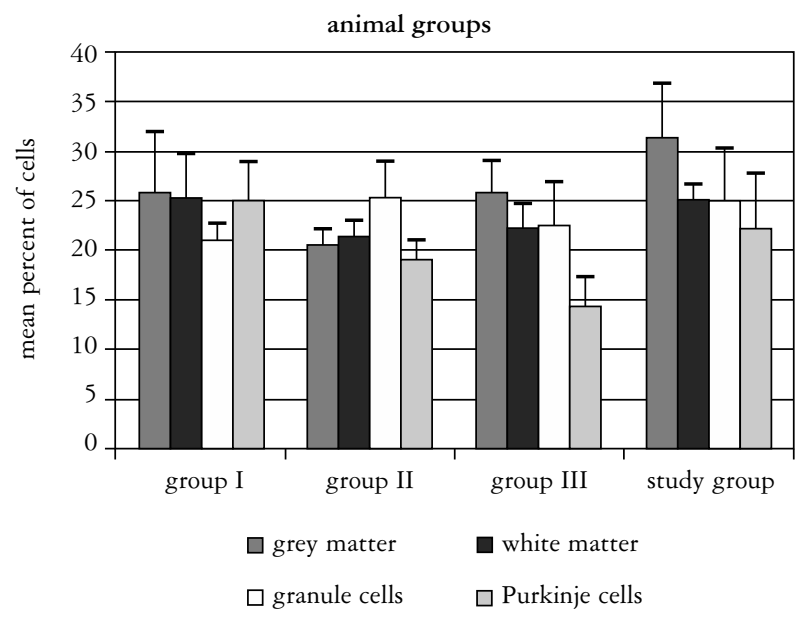

Fig. 3. Percentage of cells with active caspase-9 in rat brains in all four groups

Table IV. Statistically significant differences for brain structures found either in grey matter or in Purkinje cells of the cerebellum

\begin{tabular}{lccc}
\hline BRAIN STRUCTURE & ANOVA & POST HOC TEST & P \\
\hline Grey matter & $\mathrm{p}=0.0085$ & group II - group IV & $<0.01^{* *}$ \\
\hline Purkinje cells & $\mathrm{p}=0.0033$ & group I - group III & $<0.01^{* *}$ \\
& & group III - group IV & $<0.05^{*}$ \\
\hline
\end{tabular}


bellum. This is connected with a previous study, which suggested higher sensitivity of white matter cells and Purkinje cells to biochemical changes caused by the aging process [12]. White matter cells are characterized by increased sensitivity to free radicals. It is connected with their structure, which is rich in lipids and with a lower level of glutathione and other antioxidants. It results in higher susceptibility of this brain region to damage caused by oxidative stress. The higher level of cells with oxidative damage in DNA in white matter of the corpus callosum in aging rats is confirmed by a previous study [12]. Simultaneously, atrophy of neurons in this brain region was discovered. Moreover, reduction of its integrity in human brain was recorded. It was proved by $15 \%$ loss in white matter volume in aged people in comparison with the young [13].

In the central nervous system of aging rats almost $25 \%$ of Purkinje cells die [13]. Such significant loss of those cells may be connected with the fact that Purkinje cells are big cells with a high metabolic demand. They are also characterized by higher sensitivity to stress factors, especially in comparison with granule cells of the cerebellum. As soon as in 12-month old rats, in Purkinje cells there may accumulate lipofuscin, which has an influence on degradation of these cells long before aging [12]. Moreover, glutamate has a cytotoxic effect on Purkinje cells because they have strongly expanded dendritic fields with a large amount of receptors for this neurotransmitter [14]. In people, degeneration of cells of the cerebellum starts at about 50 years of age and may produce disorders in movement coordination.

We demonstrated that in analyzed brain regions, after administration of water by intragastric catheter, an increase in the level of cells with active caspase- 3 was observed. Similar results were observed when mice were treated with an external stress factor, such as a magnetic field with low frequency and prolonged halothane narcosis [15]. It also caused an increased percentage of cells with active caspase- 3 . It seems that the action of any stress factors leads to cleavage of procaspase-3 to caspase-3. Apoptosis activation is probably connected with protection after the disadvantageous necrotic pathway of cell death.

In this study we administered memantine to aging rats. Memantine is dependent on potential NMDA receptor blocker. It protect neurons after excitotoxic action of glutamate [16]. Memantine reduces memory deficiency in experimental animals [17], attenuates memory impairment caused by lipopolysaccharide [18] and protects the brain cortex and hippocampus after damage [19]. We administered memantine to aging animals in a neuroprotective dose of $20 \mathrm{mg} / \mathrm{kg} /$ day for 14 days. We demonstrated that memantine caused an increase of the number of cells with active caspase-3 in grey matter of the parietal lobe and white matter of the corpus callosum. But it does not affect the cells in the cerebellum. Memantine administered to aging rats acts more intensively in grey matter of the parietal lobe, because in this brain region it led to a more visible increase in the number of cells with active caspase-3. It probably indicates the restitution of the apoptosis mechanism.

\section{Caspase-9 activation in rat brains}

Because caspase- 3 is an effector caspase, we tested how its activation is connected with one of two initiator caspases, namely caspase- 9 . The role of caspase- 9 is crucial for the brain. It is not only necessary in postnatal life, but is required in embryonal development of the brain. Mice mutations with a knockout caspase-9 gene (Casp9-/-) were in most cases lethal. The most homozygous mutants died perinatally with a notably enlarged cerebrum, caused by reduction of apoptosis in the early phases of brain development [20]. The consequence of lack of apoptosis is an extensive expansion of the proliferative zone of the cerebrum, which causes a lot of malformation in caspase-9 deficient animals, such as protrusion of brain mass, stenosis of ventricles, heterotopias, invagination and interruption of the telencephalic wall [20]. Previous data [21] suggest that caspase-9 and caspase- 3 act on the same biological pathway. It is connected with similar phenotype of mutant mice with caspase- 9 and caspase- 3 deficiency. Both types of mutants had large deformations of the cerebrum caused by decreased apoptosis in proliferative neuroepithelium. Moreover, in vitro depletion of caspase-9 from cytosolic fractions resulted in the failure of caspase-3 activation [22]. These data suggest that caspase- 9 and caspase- 3 act on the same apoptotic pathways.

Interestingly, we found that in all analyzed groups there exists the same correlation as in the case of caspase- 3 . The number of cells with active caspase- 9 in young rats is similar in all analyzed structures of the brain. No heterogeneity is found, which suggest that apoptosis in young brains, without any stress factors acting, is initiated with the same frequency both in structures connected with cognitive functions and in cerebellum connected with motor functions.

In aging rats we observed a decrease in the number of cells with active caspase-9. It is probably connected with the same model as in caspase-3. Inversely to increasing age, the number of cells with active caspase- 9 is reduced. We suppose that it has the same molecular basis as in the case of caspase-3. Increasing age causes reduction of the capacity for expression of the caspase-9 gene. That results in reduction in biosynthesis of procaspase-9, which is cleaved into the active form after action of an apoptosis-stimulating factor. As in the case of caspase- 3 , the most marked decrease in the number cells with active caspase-9 occurred in Purkinje cells in the cerebellum. This means that not only the effector phase of apoptosis is reduced in those cells, but also 
the initiator phase. Thus, aging has a negative influence on at least two of three apoptotic phases, which has implications for the third phase: execution. The fewer cells are activated, the fewer of them die.

In animals with stress caused by administration of water by intragastric catheter we demonstrated an increase in the number of cells with active caspase- 9 . Therefore we confirmed the theory presented above when discussing the results of caspase-3. Briefly, it is highly probable that any stress causes gradual restoration of apoptosis to the baseline that we observed in young rats. The most effective increase in the number of cells with active form of caspase- 9 was observed in grey matter of the parietal lobe and white matter of the corpus callosum. Interestingly, the percentage of Purkinje cells was still decreasing. These data suggest that when in Purkinje cells apoptosis starts to decrease in activity during the aging process, even an additional stress factor is not able to restore the process to its normal previous state.

We also used memantine to test whether this drug has any positive impact on the initiator phase of apoptosis. We administered memantine to the study group of rats in the neuroprotective dose of $20 \mathrm{mg} / \mathrm{kg} / \mathrm{day}$ for 14 days. We found that memantine acts as a stimulus that causes increased apoptosis. Memantine caused amplification of apoptosis in grey matter of the parietal lobe, white matter of the corpus callosum and within the granule cells of the cerebellum. These results confirm the neuroprotective action of memantine. Only in the Purkinje cells of the cerebellum does memantine not cause intensification of apoptosis. This is in agreement with results obtained from caspase- 3 activation in these cells.

In conclusion, after detailed study on selected elements of cell elimination in young and aging rats' brains, we can look for some beneficial effect of memantine. The results obtained in this study seem to confirm the neuroprotective effect of memantine on increasing levels of cells with active caspase- 3 and active caspase- 9 . It probably improves caspase-dependent apoptosis in the aging brain. This beneficial result after administration of the neuroprotective drug appears to be effective only in some structures of the brain.

\section{The authors declare no conflict of interest.}

\section{References}

1. Harman D. The aging process. Proc Natl Acad Sci U S A 1981; 78: 7124-7128.

2. Zheng J, Edeelman SW, Tharmarajah G, et al. Differential patterns of apoptosis in response to aging in Drosophila. PNAS 2005; 102: $12083-12088$.

3. Finch CE. Neuron atrophy during aging: programmed or sporadic? Trends Neurosci 1993; 16: 104-110.

4. Williams GT, Smith CA. Molecular regulation of apoptosis: genetic controls on a cell death. Cell 1993; 74: 777-779.
5. Gupta S. Molecular steps of death receptor and mitochondrial pathways of apoptosis. Life Sci 2001; 69: 2957-2964.

6. Płaźnik A, Tarach E, Lehner M. Antagoniści receptora NMDA $i$ ich rola w leczeniu chorób neurodegeneracyjnych. Neurologica 2004; 4: 4-5.

7. Glick R, Bondareff W. Loss of synapses in the cerebellar cortex of senescent rats. J Gerontol 1979; 34: 818-822.

8. Anglade P, Vyas S, Hirsh EC. Apoptosis in dopaminergic neurons of human substantia nigra during normal aging. Histol Histopathol 1989; 12: 603-610.

9. Giorgio A, Santelli L, Tomassini V, et al. Age-related changes in grey and white matter structure thoughout adulthood. Neuroimage 2010; 51: 943-951.

10. Zhang AQ, Gao LJ, Wu Y, et al. Expression of caspase-3 in rodent and monkey brain: a species and age-related study. Chin J Clin Rehab 2006; 10: 180-183.

11. Mooney S, Miller MW. Expression of bcl-2, bax and caspase-3 in the brain of the developing rat. Dev Brain Res 2000; 123: 103-117.

12. Dorszewska J. Wybrane czynniki apoptotyczne w procesie starzenia się mózgu. Poznań 2003.

13. Akiyama H, Meyer JS, Mortel KF. Normal human ageing: factors contributing to cerebral atrophy. J Neurolog Sci 1997; 152: $39-49$.

14. O'Hearn E, Molliver ME. Neurotoxins and neuronal death: an animal model of excitotoxicity. Cell Death and Diseases of the Nervous System. Koliatsos VE (ed). Humana Press, Totowa 1999; 221-245.

15. Bianchi SL, Tran T, Liu ChL, et al. Brain and behaviour changes in 12-month-old $\mathrm{Tg} 2576$ and nontransgenic mice exposed to anesthetics. Neurobiol Aging 2008; 29: 1002-1010.

16. Misztal M, Frankiewicz T, Parsons CG, et al. Learning deficits induced by chronic intraventricular infusion of quinolinic acid - protection by MK-801 and memantine. Eur J Pharmacol 1996; 296: 1-8.

17. Zajączkowski W, Quack G, Danysz W. Infusion of (+)-MK801 and memantine - contrasting effects on radial maze learning in rats with entorhinal cortex lesion. Eur J Pharmacol 1995; 677: $239-246$

18. Rosi S, Vazdarjanova A, Ramirez-Amaya V, et al. Memantine protects against LPS-induced neuroinflammation, restores behaviorally-induced gene expression and spatial learning in the rat. Neuroscience 2006; 142: 1303-1315.

19. Pieta-Dias C, Martins de Lima MN, Presti-Torres J, et al. Memantine reduces oxidative damage and enhances long-term recognition memory in aged rats. Neuroscience 2007; 146: 1719-1725.

20. Kuida K, Haydar TF, Kuan CY, et al. Reduced apoptosis and cytochrome c-mediated caspase activation in mice lacking caspase 9. Cell 1998; 94: 325-337.

21. Kuida K, Zheng TS, Na S, et al. Decreased apoptosis in the brain and premature lethality in CPP32-deficient mice. Nature 1996; 384: 368-372

22. Li P, Nijhawan D, Budihardjo I, et al. Cytochrome $\mathrm{c}$ and dATPdependent formation of Apaf1/caspase-9 complex initiates an apoptotic protease cascade. Cell 1997; 86: 479-489.

\section{Address for correspondence}

\section{Andrzej Marszałek, MD, PhD}

Collegium Medicum Nicolaus Copernicus University

Department of Clinical Pathomorphology

M. Skłodowskiej-Curie 9

85-094 Bydgoszcz

tel. +48525854200

fax +48525854049

e-mail: amars@cm.umk.pl 